KAREN C. GAREIS Goodman Research Group, Inc.

ROSALIND CHAIT BARNETT Brandeis University*

KAREN A. ERTEL Harvard School of Public Health**

LISA F. BERKMAN Harvard School of Public Health***

\title{
Work-Family Enrichment and Conflict: Additive Effects, Buffering, or Balance?
}

We used data from the Midlife Development in the United States (MIDUS I) (N =2,031) to compare three models of how work-family conflict and enrichment might operate to predict well-being (mental health, life satisfaction, affect balance, partner relationship quality). We found no support for a relative-difference model in which the conflict-enrichment balance predicted outcomes. In the work-to-family direction, the additive model fit best: Both workto-family conflict and work-to-family enrichment were independently linked to outcomes. In the family-to-work direction, the interactive model fit best: Family-to-work enrichment buffered the negative outcomes ordinarily linked to familyto-work conflict. Enrichment is key because with

Goodman Research Group, Inc., 955 Massachusetts Avenue, Suite 201, Cambridge, MA 02139 (Karen.Gareis@gmail.com).

*Brandeis University, Women's Studies Research Center, Mailstop 079, 515 South Street, Waltham, MA 02453-2720.

**Harvard School of Public Health, Department of Society, Human Development and Health, Room 441, 4th Floor, Landmark West, 401 Park Drive, Boston MA 02115.

***Harvard School of Public Health, Center for Population and Development Studies, 9 Bow Street, Cambridge, MA 02138.

Key Words: families and work, well-being, work family balance. the additive model, it contributed incremental explanatory power, and with the buffering model, it conditioned conflict-outcome relationships. Work-to-family conflict and family-towork enrichment appeared particularly salient for well-being.

Increases in dual-earner families, single parents, and families with both child- and elder-care responsibilities have spurred research on the work-family interface in the past 30 years. How employees manage work and family roles has major implications for well-being, job performance, and family functioning. Difficulty managing these key social roles can be a major stressor, affecting role-related outcomes as well as overall health and well-being (Frone, 2003).

The dominant assumption in the workfamily literature has been-and largely still is - that these spheres of life are separate and compete for such scarce resources as time and attention (Barnett, 1998). The original focus on conflict still characterizes the work-family literature more than 20 years after Greenhaus and Beutell's (1985) influential paper on workfamily conflict (Greenhaus \& Powell, 2006). Growing evidence of work-family synergy (e.g., Bailyn, 1993) and salutary effects of multiple-role involvement (e.g., Barnett \& Hyde, 
2001; Marks \& MacDermid, 1996), however, has challenged the conflict assumption. Workfamily scholars (e.g., Greenhaus \& Parasuraman, 1999; Grzywacz \& Marks, 2000) have called for greater attention to the flipside of work-family conflict: work-family enrichment, or " the extent to which experiences in one role improve the quality of life in the other role" (Greenhaus \& Powell, p. 73).

Greenhaus and Beutell (1985) defined workfamily conflict as bidirectional, so the term, used generically, includes both work-to-family conflict and family-to-work conflict. Each direction of influence is assumed to have different antecedents and, in some cases, different consequences (Frone, Russell, \& Cooper, 1992; Gutek, Searle, \& Klepa, 1991). For example, long work hours may predict workto-family conflict, whereas heavy elder-care demands may predict family-to-work conflict. Each type of conflict is assumed to predict rolerelated outcomes in the same domain, whereas both types of conflict may predict general mental and physical health (Frone, 2003). Thus, family-to-work conflict may predict poor job performance, work-to-family conflict may predict poor family relationships, and both forms of conflict may predict lower well-being.

Compared to work-family conflict, workfamily enrichment receives comparatively little attention and remains conceptually and empirically underdeveloped (Frone, 2003; Witt \& Carlson, 2006), although several researchers have recently begun addressing this gap (e.g., Greenhaus \& Powell, 2006; Grzywacz \& Bass, 2003). As yet, there is no real consensus on terminology (Frone, 2003), although Carlson, Kacmar, Wayne, and Grzywacz (2006) offered a useful taxonomy. We use the term work-family enrichment, defined by Carlson et al., as occurring when resources and experiences gained from one role improve role performance and quality of life in the other role. That definition best characterizes the items assessing positive aspects of the work-family interface in the data set we used for our analyses.

Work-family enrichment, like conflict, is defined as bidirectional (Greenhaus \& Powell, 2006), so, again, the generic term includes both work-to-family and family-to-work enrichment. Thus, a partner might offer a suggestion to better perform a work task, or a productive day at work might translate to more attentive interactions with family at home. The fourfold taxonomy of work-to-family and family-to-work conflict and enrichment has received empirical support in several studies (e.g., Grzywacz \& Marks, 2000).

Though much of the literature continues to conceptualize work-family balance merely as an absence of conflict (Frone, 2003), scholars have recently begun integrating the constructs of conflict and enrichment to paint a fuller picture of the work-family interface. First, several theorists have noted that work-family conflict and enrichment are not necessarily parallel concepts; they may involve somewhat different underlying processes and predict somewhat different outcomes (Frone, 2003; Witt \& Carlson, 2006). Second, as noted above, some researchers are now incorporating positive aspects of the workfamily interface into their models, and a few have gone further, specifying how the positive and negative aspects of the interface might combine to produce outcomes. For example, Greenhaus and Powell (2006) speculated that beyond having main effects, enrichment could buffer people from the negative consequences of workfamily conflict. Still, most research in this area only tests a simple additive relationship, with conflict and enrichment modeled as independent predictors. Yet such additive models are only one of several possible ways to conceptualize the work-family interface.

In one of the only studies to compare different theoretically derived models of the work-family interface, Grzywacz and Bass (2003) used data from Wave 1 of the National Survey of Midlife Development in the United States (MIDUS I) to examine alternative ways of combining conflict and enrichment to predict dichotomous mental disorder outcomes. The theoretical framework was based on family resilience theory (e.g., Patterson, 2002), which elucidates the processes by which a family's resources or capabilities allow it to thrive in the face of risk. Resources (operationalized as enrichment) may allow families to evaluate demands (operationalized as conflict) as nonthreatening, not requiring further attention. This is termed an elimination strategy because resources allow what might be a potential threat to be defined as a nonthreat. Operationally, this process is reflected in the independent-effects (or additive) model of conflict and enrichment most commonly reported in the literature. The buffering relationship hypothesized by Greenhaus and Powell (2006), reflected in an interaction-effects (or buffering) model, is also an elimination 
strategy in which enrichment buffers negative outcomes to a greater degree under conditions of high conflict than low. For example, there may be an additive effect in which conflict could occur at home over an employee missing family activities because of work demands, but, at the same time, the job has rewards that make the employee a better companion at home. In an interactive or buffering effect, being a better companion may take on a stronger buffering role when the employee is missing more (vs. fewer) family activities.

Alternatively, enrichment may allow families to acknowledge conflict as a threat, but as one that is manageable on the basis of an evaluation of the extent to which family capabilities (enrichment) exceed those demands (conflict). This is termed an assimilation strategy because the threat is acknowledged but deemed manageable to the degree to which it can be assimilated into the family's structures and functions. For example, an employee may explicitly assess the degree to which working harder at the job to provide for family needs can override the fact that family worries and problems may be distracting on the job. The assimilation strategy focuses explicitly on the balance between resources and demands; thus, it can be operationalized as a relative-difference (or balance) model in which the predictor is enrichment minus conflict.

Grzywacz and Bass (2003) found that conflict and enrichment had additive effects on depression and problem drinking but interactive effects on anxiety disorder; that is, enrichment buffered the negative relationship between conflict and anxiety. Thus, different models of the work-family interface were supported for different outcomes, but all reflected elimination, not assimilation. Grzywacz and Bass suggested that the exact processes may differ by outcome. Specifically, the authors argued that anxiety is more sensitive than depression to the absence of family resources in the face of family stress. These findings suggest that research on a greater variety of outcomes is needed to further elucidate the conditions under which conflict and enrichment have additive versus interactive or buffering effects, or whether there are outcomes for which a relative-difference or balance model provides the best fit.

To our knowledge, no other researchers have compared different models of the work-family interface. We extended the Grzywacz and Bass (2003) analysis using the same MIDUS I data set to compare the additive, interactive, and relative-difference models of conflict and enrichment as predictors of an expanded set of socioemotional well-being outcomes, including self-rated mental health, life satisfaction, affect balance (i.e., positive vs. negative mood), and, for partnered respondents, partner relationship quality. We examined different outcomes because of the implication of Grzywacz and Bass's findings that underlying processes may differ by outcome. We also explored whether their findings generalize to an interrelated set of more everyday socioemotional wellbeing outcomes beyond relatively rare mental disorders (in MIDUS I, only $3.8 \%-13.9 \%$ of respondents had the disorders examined by Grzywacz and Bass).

MIDUS I is particularly useful for addressing our research questions because it is a large, national data set with measures of work-family enrichment as well as conflict. Further, because it is a study of health, it contains data on a variety of well-being outcomes. (Note that the recently available MIDUS Wave 2 data do not suit our purposes well because we prefer to maximize comparability to the Grzywacz and Bass, 2003, analysis; further, attrition and respondent retirement have reduced the eligible sample by half at Wave 2, and respondents were 10 years older and, on average, at an easier-tomanage stage in work and family life.)

Consistent with Grzywacz and Bass (2003), covariates in our analysis were age, gender, racial or ethnic minority status, education, income, partnered status (excluded for relationship quality, which was only assessed for partnered respondents), presence of young children, self-employed status, and work hours. Gender was included because work and family responsibilities are gendered (Barnett, 1998), and well-being outcomes may differ for men and women (Shmotkin, 1990). Work-family experiences are clearly conditioned by the presence of partners and young children and by work hours (Barnett; Kossek \& Ozeki, 1998). Finally, following Frone (2000), age, racial or ethnic minority status, education, income, and selfemployment were included because both workfamily experiences and well-being are related to life course stage, socioeconomic factors, and employment situation (Grzywacz \& Bass).

In addition to the Grzywacz and Bass (2003) covariates, we added negative affectivity, operationalized as neuroticism, to address 
common-method bias (Burke, Brief, \& George, 1993). Self-report measures of predictors and outcomes may reflect a common underlying response bias, spuriously inflating relationships (Allen, Herst, Bruck, \& Sutton, 2000). Although questions remain about whether negative affectivity is best treated as a methodological nuisance variable (e.g., Burke et al.) or a dispositional variable (e.g., Grzywacz \& Marks, 2000), it is clear that it is important to control for negative affectivity in studies of the work-family interface.

\section{METHOD}

\section{Participants}

Wave 1 of MIDUS collected data in 1995-1996 from English-speaking adults aged 25-74 in the coterminous United States. The core sample was obtained through random digit dialing. Our analyses included employed core sample respondents who completed work-family measures $(N=2,031 ; 1,075$ men, 956 women). Our sample was $87.6 \%$ White, $6.6 \%$ Black, and $1.3 \%$ Asian; $4.5 \%$ described themselves as multiracial or other. About one third $(34.0 \%)$ had a bachelor's degree or higher. The median annual household income was $\$ 47,000$. Some $23.8 \%$ of the sample, however, had a household income $\leq \$ 25,000$, and $37.8 \%$ had income $\leq \$ 35,000$. On average, respondents worked 44.2 hours per week $(S D=14.6)$. The majority $(64.3 \%)$ were married or living with a partner; of those, $74.9 \%$ had employed partners working an average of 41.0 hours per week $(S D=13.4)$; thus, $48.2 \%$ were in dual-earner couples. Fully $44.2 \%$ had minor children at home, and $34.7 \%$ spent time each month assisting parents; some $16.8 \%$ fell into both groups and were therefore "sandwiched" by both elder- and child-care responsibilities.

\section{Procedures}

As noted, the sample was obtained through random digit dialing, with one household member aged 25-74 randomly selected to respond. Older people and men were oversampled to obtain a good distribution on the cross-classification of age and gender. If the respondent did not complete the interview, no other household member was selected. Respondents completed a 30minute telephone interview and two 45-page mailed questionnaires. The response rate was $70 \%$ for the phone interview, of whom $87 \%$ completed questionnaires for an overall response rate of $60.9 \%$. We did not use the sample weights in our analyses because our primary goal was to explore linkages among variables in this sample; therefore, we were relatively unconcerned with the population prevalence of study variables.

\section{Measures}

Multi-item scales were scored by averaging responses to the items that were answered, so even if respondents skipped some items, they still received a score. There were very little missing data, however; skip rates ranged from $0.0 \%$ to $0.9 \%$ for most items, although up to $2.0 \%$ of partnered respondents skipped relationship quality items.

Work-to-family and family-to-work conflict and enrichment were assessed with four fouritem scales developed by the MIDUS I researchers. Items including "Job worries or problems distract you when you are at home," "Responsibilities at home reduce the effort you can devote to your job," "Having a good day on your job makes you a better companion when you get home," and "Talking with someone at home helps you deal with problems at work" were rated on a scale from 1 (never) to 5 (all the time). Cronbach's $\alpha$ s were $.82, .72, .79$, and .68 for work-to-family conflict and enrichment and for family-to-work conflict and enrichment, respectively.

Respondents rated their mental or emotional health on a scale from 1 (poor) to 5 (excellent); such single-item measures have a long history in studies of health and are generally found to correlate well with longer measures and to have comparable reliability as well as concurrent and discriminant validity (e.g., DeSalvo et al., 2006).

Respondents' satisfaction with their life overall, work situation, physical health, relationship with spouse or partner (if applicable), and relationship with children (if applicable) was rated on a scale from 0 (worst) to 10 (best) and averaged to obtain a global life satisfaction score (Prenda \& Lachman, 2001). Cronbach's $\alpha$ was .64.

For affect balance, respondents rated from 1 (none of the time) to 5 (all of the time) the frequency of six types of positive affect (e.g., "cheerful") and six types of negative affect (e.g., "hopeless") over the past month. The 
MIDUS I researchers culled items from wellknown valid instruments, including the Bradburn (1969) Affect Balance Scale. Scores were computed by subtracting mean negative from mean positive affect. Cronbach's $\alpha$ was .91.

Partner relationship quality was assessed only in married or cohabiting respondents using a measure adapted by MIDUS I researchers from Schuster, Kessler, and Aseltine (1990). Respondents rated six support items (e.g., "How much does your spouse or partner really care about you?') and six strain items (e.g., "How often does your spouse or partner criticize you?"') on a scale from 1 (never) to 4 (often). Scores were computed by subtracting mean strains from mean support. Cronbach's $\alpha$ was .91.

\section{Covariates}

To compute age, respondent birthdate was subtracted from the interview date. Gender was coded as $1=$ male and $2=$ female. Racial or ethnic minority status was coded as $0=$ White, $1=$ other. Educational level was coded as three dichotomous variables: high school diploma or GED, some college or associate's degree, and college degree and above; the reference category was less than a high school diploma. For household income, response scales were categorical (e.g., $\$ 40,000-\$ 44,999$ ), so responses were converted to the category midpoint before summing. Marital status was coded as two dichotomous variables: divorced or separated and never married or widowed; the reference category was married or cohabiting. Presence of young children $(0-6$ years $)$ and self-employed status were coded as $0=n o$, $1=$ yes. Total work hours was the summed average weekly work hours for all jobs. Negative affectivity was assessed via the neuroticism subscale from a longer personality measure (Lachman \& Weaver, 1997). Respondents rated how well four traits-moody, worrying, nervous, and calm (reversed)-described them on a scale from 1 (not at all) to 4 (a lot). Cronbach's $\alpha$ was .74.

\section{Analytic Strategy}

We first estimated a baseline set of simultaneous ordinary least squares multiple regression models predicting well-being outcomes from covariates. To test Model 1 (additive effects), we entered the four work-family interface components - work-to-family and family-towork conflict and enrichment - to the baseline model. To test Model 2 (interactive or buffering effects), we added two interaction terms, Workto-family conflict $\times$ Enrichment and Familyto-work conflict $\times$ Enrichment, to Model 1 . A significant increment to $R^{2}$ for Model 2 over Model 1 would constitute evidence for buffering. Finally, to test Model 3 (relative-difference or balance effects), we added two difference score terms, work-to-family enrichment - conflict and family-to-work enrichment-conflict, to the baseline model. To evaluate the fit of Model 3 , which was not nested within the other models, we compared the increment to adjusted $R^{2}$ associated with the addition of the work-family balance terms to the baseline model with the increments to adjusted $R^{2}$ associated with the addition of the work-family variables to the two competing models.

\section{RESULTS}

Table 1 shows descriptive statistics. On average, respondents rated both kinds of enrichment as more frequent than both kinds of conflict. They rated family as enriching work more often than the reverse, whereas they rated work as conflicting with family more often than the reverse. There did not appear to be a great degree of distress in the sample, with means closer to the positive end of all four well-being measures. As expected, well-being outcomes were moderately interrelated, with correlations ranging from .25 for relationship quality and mental health to .55 for life satisfaction and affect balance (correlational results available from authors).

Table 2 shows the model comparison results. For Model 1, the four work-family predictors operated in the expected direction with one exception: Work-to-family enrichment predicted significantly poorer relationship quality, but the magnitude of this beta coefficient was comparatively small. For Model 2, for all four outcomes, increment to adjusted $R^{2}$ associated with the inclusion of the interaction terms was significant, indicating that the interactive or buffering models explained a significantly greater proportion of the variance than did the corresponding additive models (Model 1). For three outcomes (mental health, life satisfaction, and affect balance), the increment to 
Table 1. Descriptive Statistics for Study Variables

\begin{tabular}{|c|c|c|c|}
\hline Variable & Mean or Percentage & $S D$ & Range \\
\hline \multicolumn{4}{|l|}{ Predictors } \\
\hline $\mathrm{W}>\mathrm{F}$ conflict & 2.64 & 0.73 & $1-5$ \\
\hline $\mathrm{W}>\mathrm{F}$ enrichment & 2.88 & 0.74 & $1-5$ \\
\hline $\mathrm{F}>\mathrm{W}$ conflict & 2.09 & 0.64 & $1-5$ \\
\hline $\mathrm{F}>\mathrm{W}$ enrichment & 3.34 & 0.77 & $1-5$ \\
\hline \multicolumn{4}{|l|}{ Outcomes } \\
\hline Mental health & 3.81 & 0.91 & $1-5$ \\
\hline Life satisfaction & 7.69 & 1.16 & $3-10$ \\
\hline Affect balance & 1.86 & 1.18 & $-4-+4$ \\
\hline Relationship quality & 1.37 & 1.03 & $-3-+3$ \\
\hline \multicolumn{4}{|l|}{ Covariates } \\
\hline Age & 43.85 & 11.14 & $20-74$ \\
\hline Male & $52.9 \%$ & & \\
\hline Racial or ethnic minority & $12.4 \%$ & & \\
\hline \multicolumn{4}{|l|}{ Educational level } \\
\hline Less than high school & $5.8 \%$ & & \\
\hline High school/GED & $27.7 \%$ & & \\
\hline Some college & $32.5 \%$ & & \\
\hline College degree+ & $34.0 \%$ & & \\
\hline Household income & $58,876.40$ & $47,449.20$ & $0-87,500.00$ \\
\hline \multicolumn{4}{|l|}{ Marital status } \\
\hline Married/partnered & $64.3 \%$ & & \\
\hline Divorced/separated & $20.0 \%$ & & \\
\hline Single/widowed & $15.7 \%$ & & \\
\hline Young children & $17.3 \%$ & & \\
\hline Self-employed & $17.9 \%$ & & \\
\hline Work hours & 44.17 & 14.57 & $2-142$ \\
\hline Negative affectivity & 2.23 & 0.66 & $1-4$ \\
\hline
\end{tabular}

Note. $N=2,031(52.9 \%$ men and $47.1 \%$ women) except relationship quality, which was only assessed in partnered respondents ( $n=1,414 ; 58.8 \%$ men and $41.2 \%$ women). $\mathrm{W}>\mathrm{F}=$ work-to-family; $\mathrm{F}>\mathrm{W}=$ family-to-work.

$R^{2}$ appeared to be driven by buffering in the family-to-work direction; that is, the family-towork interaction term was significant, whereas the work-to-family interaction term was not. For relationship quality, both interaction terms were significant, but the beta coefficient for the family-to-work term was notably larger.

For Model 3, the work-to-family and familyto-work balance terms were linked to well-being outcomes in the expected direction, with one exception: For relationship quality, the workto-family balance term was not significant, as expected given the above-mentioned unexpected association between work-to-family enrichment and poorer relationship quality. As shown in Table 2, Model 2 (interactive effects) was the best fit for all four outcomes. In terms of effect size, Cohen's $d$ ' (Cohen, 1988) for the workfamily interface components of Model 2 was 0.45 (classified as a moderate effect) for mental health, 0.92 (large effect) for life satisfaction, 0.64 (moderate effect) for affect balance, and 1.17 (very large effect) for relationship quality.

Three of these linkages appeared to be driven by buffering in the family-to-work direction, as discussed above. Thus, for this set of wellbeing outcomes, buffering was consistently supported in the family-to-work direction. Figure 1 shows the buffering effect for mental health; graphs for the other outcomes showed similar patterns. The poorest outcomes were associated with high family-to-work conflict combined with low offsetting family-to-work enrichment. In contrast, high family-to-work enrichment appeared to mitigate the negative links between family-to-work conflict and wellbeing, especially when conflict was high.

For the work-to-family direction, Model 1 (additive effects) was the most parsimonious. This conclusion is supported by a set of analyses 
Table 2. Comparing Different Models of the Work-Family Interface in Predicting Socioemotional Well-Being

\begin{tabular}{|c|c|c|c|c|c|c|c|c|c|}
\hline \multirow[b]{2}{*}{ Variable } & \multicolumn{3}{|c|}{ Model 1: Additive Effects } & \multicolumn{3}{|c|}{ Model 2: Interactive Effects } & \multicolumn{3}{|c|}{ Model 3: Relative Difference } \\
\hline & $B$ & $S E B$ & $\beta$ & $B$ & $S E B$ & $\beta$ & $B$ & $S E B$ & $\beta$ \\
\hline \multicolumn{10}{|l|}{ Self-rated mental health } \\
\hline $\mathrm{W}>\mathrm{F}$ conflict & -.128 & .032 & $-.102^{* * *}$ & -.127 & .032 & $-.101^{* * *}$ & - & - & - \\
\hline $\mathrm{W}>\mathrm{F}$ enrichment & .063 & .028 & $.051^{*}$ & .069 & .028 & $.056^{* *}$ & - & - & - \\
\hline $\mathrm{F}>\mathrm{W}$ conflict & -.176 & .035 & $-.124^{* * *}$ & -.179 & .036 & $-.126^{* * *}$ & - & - & - \\
\hline $\mathrm{F}>\mathrm{W}$ enrichment & .138 & .027 & $.117^{* * *}$ & .151 & .027 & $.127^{* * *}$ & - & - & - \\
\hline $\mathrm{W}>\mathrm{FC} \times \mathrm{W}>\mathrm{FE}$ & - & - & - & -.016 & .030 & -.012 & - & - & - \\
\hline $\mathrm{F}>\mathrm{WC} \times \mathrm{F}>\mathrm{WE}$ & - & - & - & .131 & .034 & $.083^{* * *}$ & - & - & - \\
\hline $\mathrm{W}>\mathrm{FE}-\mathrm{W}>\mathrm{FC}$ & - & - & - & - & - & - & .090 & .020 & $.102^{* * *}$ \\
\hline $\mathrm{F}>\mathrm{WE}-\mathrm{F}>\mathrm{WC}$ & - & - & - & - & - & - & .154 & .020 & $.169^{* * *}$ \\
\hline Increment to adjusted $R^{2}$ & & .043 & & & .049 & & & .042 & \\
\hline \multicolumn{10}{|l|}{ Life satisfaction } \\
\hline $\mathrm{W}>\mathrm{F}$ conflict & -.517 & .037 & $-.324^{* * *}$ & -.506 & .037 & $-.317^{* * *}$ & - & - & - \\
\hline $\mathrm{W}>\mathrm{F}$ enrichment & .156 & .032 & $.099^{* * * *}$ & .173 & .033 & $.110^{* * *}$ & - & - & - \\
\hline $\mathrm{F}>\mathrm{W}$ conflict & -.179 & .041 & $-.099^{* * *}$ & -.194 & .041 & $-.107^{* * *}$ & - & - & - \\
\hline $\mathrm{F}>\mathrm{W}$ enrichment & .345 & .031 & $.229^{* * *}$ & .360 & .031 & $.239^{* * *}$ & - & - & - \\
\hline $\mathrm{W}>\mathrm{FC} \times \mathrm{W}>\mathrm{FE}$ & - & - & - & .056 & .034 & .032 & - & - & - \\
\hline $\mathrm{F}>\mathrm{WC} \times \mathrm{F}>\mathrm{WE}$ & - & - & - & .127 & .039 & $.063^{* *}$ & - & - & - \\
\hline $\mathrm{W}>\mathrm{FE}-\mathrm{W}>\mathrm{FC}$ & - & - & - & - & - & - & .316 & .023 & $.279^{* * *}$ \\
\hline $\mathrm{F}>\mathrm{WE}-\mathrm{F}>\mathrm{WC}$ & - & - & - & - & - & - & .290 & .024 & $.249^{* * *}$ \\
\hline Increment to adjusted $R^{2}$ & & .170 & & & .175 & & & .154 & \\
\hline \multicolumn{10}{|l|}{ Affect balance } \\
\hline $\mathrm{W}>\mathrm{F}$ conflict & -.344 & .034 & $-.213^{* * *}$ & -.334 & .034 & $-.207^{*}$ & - & - & - \\
\hline $\mathrm{W}>\mathrm{F}$ enrichment & .055 & .030 & $.034^{\dagger}$ & .071 & .031 & $.045^{* * *}$ & - & - & - \\
\hline $\mathrm{F}>\mathrm{W}$ conflict & -.197 & .038 & $-.108^{* * *}$ & -.211 & .038 & $-.115^{* * *}$ & - & - & - \\
\hline $\mathrm{F}>\mathrm{W}$ enrichment & .267 & .029 & $.175^{* * *}$ & .283 & .029 & $.186^{* * *}$ & - & - & - \\
\hline $\mathrm{W}>\mathrm{FC} \times \mathrm{W}>\mathrm{FE}$ & - & - & - & .049 & .032 & .028 & - & - & - \\
\hline $\mathrm{F}>\mathrm{WC} \times \mathrm{F}>\mathrm{WE}$ & - & - & - & .133 & .036 & $.065^{* * *}$ & - & - & - \\
\hline $\mathrm{W}>\mathrm{FE}-\mathrm{W}>\mathrm{FC}$ & - & - & - & - & - & - & .183 & .022 & $.160^{* * *}$ \\
\hline $\mathrm{F}>\mathrm{WE}-\mathrm{F}>\mathrm{WC}$ & - & - & - & - & - & - & .248 & .022 & $.210^{* * *}$ \\
\hline Increment to adjusted $R^{2}$ & & .087 & & & .092 & & & .076 & \\
\hline \multicolumn{10}{|l|}{ Relationship quality } \\
\hline $\mathrm{W}>\mathrm{F}$ conflict & -.254 & .042 & $-.172^{* * *}$ & -.237 & .041 & $-.161^{* * *}$ & - & - & - \\
\hline $\mathrm{W}>\mathrm{F}$ enrichment & -.130 & .036 & $-.089^{* * *}$ & -.096 & .036 & $-.066^{* *}$ & - & - & - \\
\hline $\mathrm{F}>\mathrm{W}$ conflict & -.330 & .045 & $-.201^{* * *}$ & -.362 & .045 & $-.221^{* * *}$ & - & - & - \\
\hline $\mathrm{F}>\mathrm{W}$ enrichment & .565 & .034 & $.407^{* * *}$ & .589 & .034 & $.424^{* * *}$ & - & - & - \\
\hline $\mathrm{W}>\mathrm{FC} \times \mathrm{W}>\mathrm{FE}$ & - & - & - & .116 & .040 & $.068^{* *}$ & - & - & - \\
\hline $\mathrm{F}>\mathrm{WC} \times \mathrm{F}>\mathrm{WE}$ & - & - & - & .216 & .045 & $.112^{* * *}$ & - & - & - \\
\hline $\mathrm{W}>\mathrm{FE}-\mathrm{W}>\mathrm{FC}$ & - & - & - & - & - & - & .035 & .034 & .032 \\
\hline $\mathrm{F}>\mathrm{WE}-\mathrm{F}>\mathrm{WC}$ & - & - & - & - & - & - & .489 & .026 & $.475^{* * *}$ \\
\hline Increment to adjusted $R^{2}$ & & .236 & & & .254 & & & .215 & \\
\hline
\end{tabular}

Note. $N=2,031$ (52.9\% men and 47.1\% women) except relationship quality, which was only assessed in partnered respondents ( $n=1,414 ; 58.8 \%$ men and $41.2 \%$ women $) . \mathrm{W}>\mathrm{F}=$ work-to-family; $\mathrm{F}>\mathrm{W}=$ family-to-work; $\mathrm{W}>\mathrm{FC}=$ work-to-family conflict; $\mathrm{W}>\mathrm{FE}=$ work-to-family enrichment; $\mathrm{F}>\mathrm{WC}=$ family-to-work conflict; $\mathrm{F}>\mathrm{WE}=$ family-to-work enrichment. Covariates were age, gender, minority status, educational level, household income, partnered status (excluded for relationship quality), presence of children aged $0-6$, self-employed status, work hours, and negative affectivity. Only work-family interface variables are shown in the table; covariates have been omitted for the sake of brevity and are available from the authors upon request. Hypothesis tests were two-tailed.

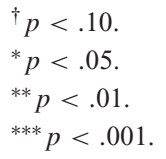


FIGURE 1. FAMILY-TO-WORK ENRICHMENT (FWE) Buffers the NEGATIVE RELATIONSHIP BETWEEN FAMILY-To-Work CONFLICT AND SElF-RATEd MENTAL HEALTH.

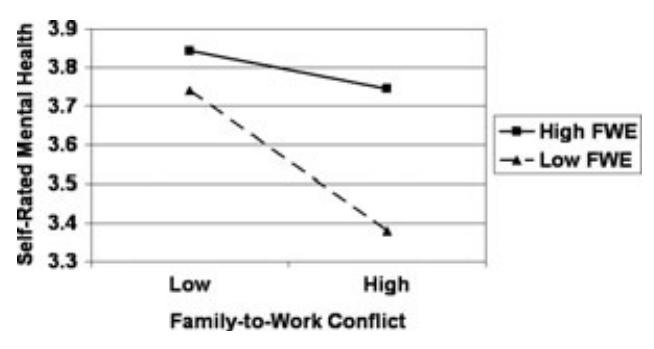

Note: "High" and "low" values correspond to $1 S D$ above and $1 S D$ below the mean, respectively.

(results available from authors) in which the family-to-work and work-to-family components of the work-family interface were separated into two sets of regression models. One set included only family-to-work components; the other included only work-to-family components. The disaggregated work-to-family analyses supported the additive model for all four outcomes, whereas the disaggregated family-towork analyses supported the interactive model for all four outcomes.

The additive models in Table 2 reveal another interesting pattern. In the work-tofamily direction, the beta coefficients for conflict exceeded those for enrichment for all outcomes; the difference was especially pronounced for life satisfaction (-.324 vs. .099) and affect balance (-.213 vs. .034). In the family-to-work direction, however, the beta coefficients for enrichment exceeded those for conflict for life satisfaction (.229 vs. - .099), affect balance (.175 vs. -.108$)$, and relationship quality (.407 vs. - .201$)$. Thus, for these outcomes, work-to-family conflict and familyto-work enrichment seemed especially salient in predicting well-being.

\section{DISCUSSION}

These findings challenge the traditional focus on work-family conflict in the research literature. Specifically, it is important to include measures of work-family enrichment in studies of the work-family interface because even in the simplest case, that of the additive model, our findings suggest that enrichment contributes incremental explanatory power over workfamily conflict alone. In the more complex case of the interactive model, enrichment is a key variable conditioning the strength of the links - or even whether there are links - between work-family conflict and several important socioemotional well-being indicators.

Our findings on the fit of the different models contrast somewhat with those of Grzywacz and Bass (2003). They found that the additive model fit best for depression and problem drinking, whereas the interactive model fit best for anxiety; in all cases, the models were the same in the work-to-family and the family-towork direction. With a different set of outcomes, however, we found a strikingly consistent pattern of relationships: The additive model fit best in the work-to-family direction, whereas the interactive model fit best in the family-to-work direction. Specifically, work-to-family conflict and work-to-family enrichment contributed independently to mental health, life satisfaction, affect balance, and partner relationship quality, whereas family-to-work enrichment buffered the negative relationships linking family-towork conflict to these outcomes. The most likely explanation for these differences is that the specific processes linking conflict and enrichment to outcomes differ somewhat depending on (a) which outcomes are studied, as noted by Grzywacz and Bass, and (b) the work-to-family or family-to-work direction of influence, as suggested by our findings.

For example, as noted above, perhaps the specific resources associated with family-towork enrichment in this study (e.g., a sense of love and respect, per one MIDUS item) allow people to better withstand family-to-work conflict (e.g., distracting worries, per another MIDUS item) without poor socioemotional consequences, as shown by the relatively flat line in Figure 1. On the other hand, when familyto-work conflict is severe enough to be linked to mental disorders, family-to-work resources may be helpful, but not to the extent that they can override the conflict-outcome link the way they may with less severe outcomes. As for the direction of influence, perhaps we do not see evidence of such buffering from work to family because the resources associated with work-tofamily enrichment in this study (e.g., specific job skills, per a MIDUS item) may not be as helpful in the family domain, at least with respect to the outcomes in this study. 
In fact, the resources flowing from work to family may differ from those flowing from family to work more generally, not just in terms of the specific measures used in MIDUS. Carlson et al. (2006) explicitly suggested that "the resources forged by one domain may be different from those initiated by another" (p. 135). In their study, they found that work and family had some types of domain-crossing resources in common (i.e., intellectual and personal development, mood gains), but other resources were uniquely associated with work to family (i.e., psychosocial capital, or a sense of accomplishment) versus family to work (i.e., efficiency or improved focus and time management). Similarly, work and family conflicts have been categorized as based on time, energy, strain, attention, and behavior (Frone, 2003; Greenhaus \& Beutell, 1985; MacDermid et al., 2000); it is likely that these are also differentially linked to the workto-family versus the family-to-work direction. Thus, future research would benefit from more fine-grained analyses of which specific resources and conflicts are associated with each direction of influence and precisely how the various types of resources and conflicts are linked to particular outcomes.

Our findings and those of Grzywacz and Bass (2003) supported some variety of elimination strategy, whether additive or interactive/ buffering, for all outcomes examined. It remains to be seen whether this holds true for additional outcomes. It may be that the poor showing of the assimilation strategy (reflected by the balance model) is related to the operationalization of balance as a simple difference score. It is not clear that this operationalization adequately reflects the considered weighing of conflict versus enrichment; future research might consider alternative ways of assessing whether and how people make such comparative evaluations. One fruitful avenue to pursue in this regard may be the extensive literature that grew out of Lazarus and Folkman's (1984) model of stress and coping, which emphasizes the role of cognitive appraisal of perceived demands versus perceived coping resources in the experience of stress. Nevertheless, taken together, the findings of these studies underscore the importance of modeling the work-family interface in different ways and testing comparative model fit. Future research should examine more role-related outcomes, particularly for work (e.g., job satisfaction, job performance, organizational commitment). Such research would help illuminate the boundary conditions under which different models operate, potentially shedding light on underlying processes linking work-family conflict and enrichment to outcomes.

The unexpected finding that work-to-family enrichment was associated with significantly poorer partner relationship quality in our data may reflect reverse causality, an issue plaguing much work-family research, most of which is cross-sectional. Perhaps respondents who have poor partner relationships cope at least partially by attending to alternative sources of success arising from their work lives (Barnett \& Hyde, 2001). This possibility is supported by a closer examination of the work-to-family enrichment items, which involve work experiences helping one deal with personal and practical issues at home, making one more interesting and a better companion at home, and being useful for things one has to do at home. Longitudinal studies are needed to disentangle the direction of causality. (Unfortunately, the 10-year period separating the MIDUS waves is likely too long to expect a link between Wave 1 work-family variables and Wave 2 socioemotional well-being.)

Questions of causality are particularly vexing in the case of family relationship quality variables, for which it is especially difficult to disentangle antecedents and outcomes. Poor relationships with family members may be a source of family-to-work conflict in themselves, as well as precluding family-to-work enrichment. In addition to work-to-family conflict-and perhaps lack of work-to-family enrichment-has the potential to disrupt family relationships, underscoring the fact that work and family experiences are not only mutually interdependent but also are recursive, with repeated feedback loops over time. Again, longitudinal or diary studies conducted over time are the best methods to illuminate these questions.

A related direction for future research is to examine the family as the unit of analysis, as called for by Barnett (1998) and Frone (2003), among others. To date, however, the work-family literature has been characterized by a focus on employees as autonomous agents rather than as members of families in which each person's work and family experiences affect those of other members, despite the fact that numerous studies provide convincing 
evidence for a systems approach to studying couples and families (e.g., Barling, 1984; Gareis, Barnett, \& Brennan, 2003; Rook, Dooley, \& Catalano, 1991).

Like Grzywacz and Bass (2003), we constructed each interaction term as a combination of conflict and enrichment operating in the same direction (i.e., from work to family and the reverse). Aside from our desire to conduct analyses comparable to those of Grzywacz and Bass, we believe it makes most sense to consider work-to-family evaluations together and family-to-work evaluations together. In evaluating trade-offs, as in the relative-difference model, it is likely that people consider the pros and cons of one domain at a time; for example, a job may be very time-consuming but at the same time provide great intellectual or financial rewards. We chose not to combine the two conflict terms and the two enrichment terms because that would likely reflect simple negative and positive response tendencies. Combining conflict in one direction with enrichment in the other direction warrants further consideration, however. As Grzywacz and Bass noted, if we conceive of family-to-work enrichment as a family's adaptive response to a member's work demands, it may be key to defusing workto-family conflict. This idea is certainly worth pursuing in further research, but because of the way the work-family predictors are assessed in MIDUS, we do not believe it is a fruitful avenue in this data set. Specifically, the family-to-work enrichment items in MIDUS address resources like advice, relaxation, love and respect, and feelings of provider responsibility, not adaptive family responses to work demands.

Other limitations of this study include the fact that the MIDUS sample is somewhat homogeneous and the overall response rate was just $60.9 \%$, raising issues of selection biases and generalizability. In a less advantaged sample, the absolute levels of conflict might be higher, enrichment might be lower, and outcomes might be worse; it is not clear, however, that the relationships linking predictors to outcomes would differ. Future research with more racially and sociodemographically diverse samples should be conducted to address this question. Also, the internal consistency of the life satisfaction and family-to-work enrichment measures was somewhat low, raising the issue of our power to detect effects. Nevertheless, we found strong links between work-family predictors and life satisfaction, and family-towork enrichment appeared to be an especially salient predictor of well-being in this study, suggesting that low power was not a serious issue in our analyses. We also relied on self-report measures, which, as noted above, can spuriously inflate relationships between predictors and outcomes. We addressed this issue to some degree by partialling out one important form of response bias, negative affectivity, but, ideally, future research should include more objective measures of health and well-being (e.g., doctor visits, work absence) and reports from family members. Future research should also assess enrichment as well as conflict, test alternative models of how these combine to produce outcomes, conduct more fine-grained process analyses, use more diverse samples, and collect longitudinal or diary data, as noted above.

In conclusion, in a comparison of three models of how work-family conflict and enrichment operate to predict socioemotional well-being, we found support for an additive model in the work-to-family direction and an interactive or buffering model in the family-to-work direction. Work-to-family conflict and familyto-work enrichment appeared especially salient for socioemotional well-being, which is interesting in light of the fact that, as noted above, these were the directions of conflict (i.e., workto-family) and enrichment (i.e., family-to-work) that respondents rated as more frequent. This relative advantage for the work role is consistent with previous research reviewed by Frone (2003), who noted that "it appears that family has a more beneficial impact on work life than work life has on family .... [C]ompared to family roles, work roles encounter lower levels of cross-role interference or conflict and higher levels of cross-role facilitation" (p. 149). The implications for employees who are trying to manage their work and family roles - or for those who would like to help them do so-are that efforts targeted at reducing work-to-family conflict and enhancing family-to-work enrichment are most likely to pay off, at least in terms of enhanced socioemotional well-being.

\section{NOTE}

This secondary analysis of MIDUS (National Survey of Midlife Development in the United States) data was funded by the Alfred P. Sloan Foundation. 


\section{REFERENCES}

Allen, T. D., Herst, D. E. L., Bruck, C. S., \& Sutton, M. (2000). Consequences associated with work-to-family conflict: A review and agenda for future research. Journal of Occupational Health Psychology, 5, 278-308.

Bailyn, L. (1993). Breaking the mold: Women, men, and time in the new corporate world. New York: Free Press.

Barling, J. (1984). Effects of husbands' work experiences on wives' marital satisfaction. Journal of Social Psychology, 124, 219-225.

Barnett, R. C. (1998). Toward a review and reconceptualization of the work/family literature. Genetic, Social and General Psychology Monographs, 124, $125-182$.

Barnett, R. C., \& Hyde, J. S. (2001). Women, men, work, and family: An expansionist theory. American Psychologist, 56, 781-796.

Bradburn, N. M. (1969). Two dimensions of psychological well-being: Positive and negative affect. In N. M Bradburn \& C. E. Noll (Eds.), The structure of psychological well-being (pp. 53-70). Chicago: Aldine.

Burke, M. J., Brief, A. P., \& George, J. M. (1993). The role of negative affectivity in understanding relations between self-reports of stressors and strains: A comment on the applied psychology literature. Journal of Applied Psychology, 78, $402-412$.

Carlson, D. S., Kacmar, K. M., Wayne, J. H., \& Grzywacz, J. G. (2006). Measuring the positive side of the work-family interface: Development and validation of a work-family enrichment scale. Journal of Vocational Behavior, 68, 131-164.

Cohen, J. (1988). Statistical power analysis for the behavioral sciences. Hillsdale, NJ: Erlbaum.

DeSalvo, K. B., Fisher, W. P., Tran, K., Bloser, N., Merrill, W., \& Peabody, J. (2006). Assessing measurement properties of two single-item general health measures. Quality of Life Research, 15, $191-201$.

Frone, M. R. (2000). Work-family conflict and employee psychiatric disorders: The National Comorbidity Survey. Journal of Applied Psychology, 85, 888-895.

Frone, M. R. (2003). Work-family balance. In J. C. Quick \& L. E. Tetrick (Eds.), Handbook of occupational health psychology (pp. 143-162). Washington, DC: American Psychological Association.

Frone, M. R., Russell, M., \& Cooper, L. M. (1992). Antecedents and outcomes of work-family conflict: Testing a model of the work-family interface. Journal of Applied Psychology, 77, 65-78.

Gareis, K. C., Barnett, R. C., \& Brennan, R. T. (2003). Individual and crossover effects of work schedule fit: A within-couple analysis. Journal of Marriage and Family, 65, $1041-1054$.
Greenhaus, J. H., \& Beutell, N. J. (1985). Sources of conflict between work and family roles. Academy of Management Review, 10, 76-88.

Greenhaus, J. H., \& Parasuraman, S. (1999). Research on work, family, and gender. In G. N. Powell (Ed.), Handbook of gender and work (pp. 391-412). Thousand Oaks, CA: Sage.

Greenhaus, J. H., \& Powell, G. N. (2006). When work and family are allies: A theory of work-family enrichment. Academy of Management Review, 31, $72-92$.

Grzywacz, J. G., \& Bass, B. L. (2003). Work, family, and mental health: Testing different models of work-family fit. Journal of Marriage and Family, $65,248-262$.

Grzywacz, J. G., \& Marks, N. F. (2000). Reconceptualizing the work-family interface: An ecological perspective on the correlates of positive and negative spillover between work and family. Journal of Occupational Health Psychology, 5, $111-126$.

Gutek, B. A., Searle, S., \& Klepa, L. (1991). Rational versus gender role explanations for workfamily conflict. Journal of Applied Psychology, 76, $560-568$.

Kossek, E. E., \& Ozeki, C. (1998). Work-family conflict, policies, and the job-life satisfaction relationship: A review and directions for organizational behavior-Human resources research. Journal of Applied Psychology, 83, 139-149.

Lachman, M. E., \& Weaver, S. L. (1997). The midlife development inventory (MIDI) personality scales: Scale construction and scoring (Technical Report No. 1). Waltham, MA: Brandeis University, Department of Psychology.

Lazarus, R. S., \& Folkman, S. (1984). Stress, appraisal, and coping. New York: Springer.

MacDermid, S. M., Barnett, R., Crosby, F., Greenhaus, J., Koblenz, M., Marks, S., PerryJenkins, M., Voydanoff, P., Wethington, E., \& Sabattini-Bunch, L. (2000). The measurement of work/life tension: Recommendations of a virtual think tank. Boston: Alfred P. Sloan Foundation.

Marks, S. R., \& MacDermid, S. M. (1996). Multiple roles and the self: A theory of role balance. Journal of Marriage and the Family, 58, 417-432.

Patterson, J. M. (2002). Integrating family resilience and family stress theory. Journal of Marriage and Family, 64, 349-360.

Prenda, K. M., \& Lachman, M. E. (2001). Planning for the future: A life management strategy for increasing control and life satisfaction in adulthood. Psychology and Aging, 16, 206-216.

Rook, K., Dooley, D., \& Catalano, R. (1991). Stress transmission: The effects of husbands' job stressors on the emotional health of their wives. Journal of Marriage and the Family, 53, $165-177$. 
Schuster, T. L., Kessler, R. C., \& Aseltine, R. H. (1990). Supportive interactions, negative interactions, and depressive mood. American Journal of Community Psychology, 18, $423-438$.

Shmotkin, D. (1990). Subjective well-being as a function of age and gender: A multivariate look for differentiated trends. Social Indicators Research, 23, $201-230$.

Witt, L. A., \& Carlson, D. S. (2006). The work-family interface and job performance: Moderating effects of conscientiousness and perceived organizational support. Journal of Occupational Health Psychology, 11, 343-357. 